\title{
Optimal Utilization Of Alternative Energy Sources
}

\author{
Duane J. Rosa, West Texas A\&M University, USA
}

\begin{abstract}
Many areas of the world today have access to alternative energy sources to meet their energy needs. A fundamental problem facing societies today is to determine the optimum utilization of energy sources. This paper analyzes the issues involving co-utilization of different types of energy production in Iceland. Formulating a dynamic social optimization problem, expressions are derived for optimal energy supply prices from each energy source. Based on the economic characteristics of the energy sources, an optimal solution is derived that involves both periods of specialization in a single energy source as well as periods of simultaneous co-utilization of available sources.
\end{abstract}

Keywords: Energy, Co-Utilization, Optimization, Geothermal, Hydropower, Iceland

\section{INTRODUCTION}

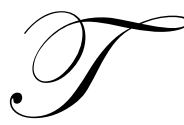

echnology today offers societies today several options in meeting their energy needs. This, however, creates a problem of selecting the optimal mix of energy sources. The solution to this problem clearly varies from one situation to another. In certain cases, the optimal energy mix will involve only one energy source. In other cases, it may involve several energy sources that may, moreover, be employed in varying proportions over time. This paper analyzes the policy issues involving co-utilization of different types of energy production. The model presented analyzes the co-utilization of geothermal and hydropower production in Iceland. Three sources of energy generation specifically relevant to Iceland, hydroelectric, geothermal and fossil fuel are considered. Even though this paper focuses on a single country, many of the results are applicable globally to the problem of an optimal energy mix.

Natural conditions in Iceland favor the increased utilization and development of hydroelectric and geothermal power production. The mean surface run-off in Iceland is about 50 liters/second/square kilometer, with a large part of the country consisting of a plateau more than 400 meters above sea level. More than half of the country is above 500 meters above sea level. The technically hydropower potential is estimated at $64 \mathrm{TWh} / \mathrm{year}$, of which 30 $\mathrm{TWh} /$ year is considered economically and environmentally harness able. In addition, Iceland has abundant geothermal energy resources. A quarter of the entire country is a volcanic area. Given that geothermal resources are not strictly renewable, it is estimated that the potential power production from this source is $20 \mathrm{TWh} / \mathrm{year}$. Present utilization of these two resources totals only $4.2 \mathrm{TWh} / \mathrm{year}$, or only about $8 \%$ of Iceland's aggregate potential (Orkustofnun - Iceland Energy Authority, 2007).

\section{HYDROPOWER PRODUCTION}

The first hydropower plant in Iceland was constructed in 1904, with a power generation capacity of 9 kilowatts. Over the years, many additional hydropower plants have been added. The first large-scale hydropower plant was built in 1965, which had a capacity of $210 \mathrm{MW}$. The total hydropower production in Iceland is now 7,289 GWH (World Energy Council, 2007). This, however, represents only a small amount of the economically feasible hydropower production for the country. Iceland is second only to Norway in the world in having the smallest per capita electric power consumption. 


\section{GEOHERMAL POWER PRODUCTION}

Iceland has enormous supplies of geothermal energy. Currently there is 2,631 GWH of installed capacity. However, it is estimated that the total potential for electricity production from the 19 high temperature fields in the country could be as high as 1,480 TWH/year. There are three types of geothermal energy: hydrothermal, geopressured and hot dry rock, the last being the most plentiful. The geothermal fields of Iceland are almost exclusively hydrothermal in nature, and this type of geothermal energy is the most useful for commercial applications. Hydrothermal areas are divided into high and low temperature fields, according to the reservoir temperature. A low temperature field is defined as one where the temperature is below 150 degrees centigrade at one kilometer in depth, and a high temperature field where the temperature is above 200 degrees centigrade. The high temperature fields of Iceland traverse the country from Southwest to Northeast, with the low temperature fields located on the flanks (Orkustofnun - Iceland Energy Authority, 2007).

Geothermal energy currently provides $26.5 \%$ of the gross energy consumption in Iceland. A very important use of this energy source is for space heating (residential and commercial), with about $87 \%$ of all buildings in Iceland being heated this way. In addition, geothermal energy is used for greenhouse cultivation of fruits and vegetables. The principal industrial uses of high temperature geothermal energy involve drying applications using flashed steam and/or hot water. Iceland has found that the most efficient way of using the high temperature fluid is to cascade its use by using the heat first for the production of electricity, and the remainder for providing for space heating, swimming pools, and even for heating sidewalks and roads. There are five major geothermal power plants in Iceland. In contrast to low temperature space heating, power production is only possible in the high temperature fields situated in the volcanic zone which lies diagonally from southwest to northeast through the country. The Svartsengi Power Plant, in the southwest of the country, currently produces 76.5 MW of electricity and about 475 liters/second of $90^{\circ}$ Centigrade hot water. The Nesjavellir Power Plant, which supplies hot water to Reykjavik, is situated in the south of the country and produces $120 \mathrm{MW}$ of electricity and about 1800 liters/second of hot water. There are three power plants that only produce electricity. The Krafla Power Plant, situated in the northeast of the country, produces $60 \mathrm{MW}$ of electricity. The Reykjanes Power-Plant, located in the southwest tip of the country produces 100 MW of electricity. The Hellisheidi Power-Plant, produce $90 \mathrm{MW}$ of electricity (Landsvirkjun - National Power Company of Iceland, 2007)

\section{ECONOMIC ANALYSIS OF ENERGY UTILIZATION}

Iceland is a country of many contrasts. While it is rich in energy resources, Iceland is a barren country. The Icelandic climate is too cold for any significant growing of crops. Therefore, a considerable part of the needed agricultural products must be imported. However, Iceland is self-sufficient in meat and dairy products and certain types of vegetables. The principal industry in Iceland is fishing. This industry, however, has been in a period of significant decline in recent years due to over fishing and reduced total catch. The principal industrial firms in the country include an aluminum smelter built in 1969 with 90,000 ton production capacity and a ferrosilicon plant. Iceland has made some attempts to attract other energy intensive industries to the country. In the 1990s, international companies started looking at Iceland as potential location for additional aluminum smelters, an industry that requires an extensive amount of available power. By 2003 Iceland had the world's highest aluminum production per capita of the population with two aluminum smelters (260,000 tons production and 300,000 people) (Hilmarsson, 2003)

In 2007, Alcoa opened a 320,000 ton aluminum smelter at Reydarfjordur in Eastern Iceland. This smelter required Landsvirkjun, The National Power Company of Iceland, to build the 690 MW Karahnjukar Hydropower plant just to provide power to the Alcoa smelter. The resulting dam, the largest in Europe, has been severely criticized by environmentalists in the country, as it flooded 57 square kilometers of pasture land (Landsvirkjun National Power Company of Iceland, 2007). In 2008, Alcoa proposed construction of an additional smelter in Husavik, northern Iceland. In addition, Nordural, a subsidiary of the U.S. firm, Century Aluminum, has proposed construction of an aluminum smelter at Helguvik Cove, in southwest Iceland. Both of these projects have been put on hold due to the recent financial collapse to hit Iceland. 
The construction and operation of aluminum smelters in Iceland has both positive and negative impacts on the country. It does bring in additional tax revenue to the country, provides additional employment during construction and final operation, and creates a positive economic multiplier effect on the other sectors of the Icelandic economy. However, from an environmental perspective, this type of industrial development brings increased pollution levels and waste disposal problems. Also, if geothermal resources are used as a power source, this can cause surface disturbances due to fluid withdrawal, noise, thermal effects, and emission of chemicals into the atmosphere.

Iceland has also considered the export of power. Feasibility studies completed by Landsvirkjun, the National Power Company of Iceland, have concluded that it would be technically feasible to export electricity through submerged ocean cable to Scotland or England (Landsvirkjun - National Power Company of Iceland, 1992). Given the distances involved (minimum of $950 \mathrm{~km}$ ), transmitting electricity through cables can only be done effectively by high voltage direct current (HVDC). When electricity is transmitted with HVDC, the alternating current is changed to direct current by rectifying it in a converter station at one end, and then changing the power to $\mathrm{AC}$ by inverting it in a converter station at the other end.

Even though a submarine cable is technically feasible and the price of Icelandic energy is competitive, Iceland would still face significant technical, economic and political obstacles. Such a project would require an enormous expenditure of funds, and this would require some cost sharing by the receiving countries. A plant would first have to be built in Iceland just to construct the cable. Also, there are some technical issues. There are currently longer undersea cables and deeper undersea cables in the world, but the undersea cable connecting Iceland to Europe would be longer and deeper than other previously constructed cables. Also, the cost effectiveness of the project will depend on market prices of energy in the future. From a political perspective, it may also be difficult for Iceland to negotiate a cost effective price, given competition from other European power producing countries (e.g. France). For the receiving countries, however, the greatest advantage may be that Iceland's electricity does not result in any environmental pollution.

There are many issues facing Iceland today as it considers development opportunities utilizing these abundant power supplies especially given the financial and economic crisis currently facing the country. Iceland is in many ways unique in terms of its available energy sources. However, most countries today face similar situations with regard to a choice of different energy sources. The following theoretical model is presented to show how a cost-effective co-utilization of different energy sources can be developed resulting in an optimal mix of energy sources.

\section{MODEL OF ENERGY CO-UTILIZATION}

In order to evaluate the potential for co-utilization of different energy sources, and to determine the optimal mix of these energy sources, the following model is developed. Consider a city with a certain population area. Let the instantaneous demand for energy in this area be given by the inverse demand function

$$
p=D(y, t)
$$

where $p$ denotes the demand price and $y$ refers to energy consumption at time t. Notice that according to this specification, the function $\mathrm{D}(\mathrm{y}, \mathrm{t})$ is time variant. We assume (i) that $\mathrm{D}(\mathrm{y}, \mathrm{t})>0$, (ii) that the function $\mathrm{D}(\mathrm{y}, \mathrm{t})$ is twice continuously differentiable and (iii) that $\mathrm{Dy}(\mathrm{y}, \mathrm{t})<0$.

Given this energy demand a measure of social benefits derived from energy use is provided by the consumer surplus defined by the following expression:

$$
B(t)=\int_{0}^{q} D(y, t) \mathrm{dy}
$$

In this case it is mathematically convenient to assume that the function $B(t)$ is concave in $q$. 
To describe a rather typical situation imagine that the population area in question is a city and the energy demand in this analysis is for residential and industrial energy purposes. Energy generation can come from three sources, geothermal, hydroelectric, and fossil fuel. Each of these three methods of energy generation involves social costs. Let us for a moment describe these costs at time $t$ by the following cost function:

$$
\mathrm{C}(\mathrm{t})=\mathrm{C}_{1}\left(\mathrm{y}_{\mathrm{G}}, \mathrm{t}\right)+\mathrm{C}_{2}\left(\mathrm{y}_{\mathrm{H}}, \mathrm{t}\right)+\mathrm{C}_{3}\left(\mathrm{y}_{\mathrm{F}}, \mathrm{t}\right)
$$

Where $y_{G}, y_{H}$, and $y_{F}$ refer to the instantaneous consumption of geothermal, hydroelectric, and fossil energy respectively and the functions $\mathrm{C}_{1}(\cdot), \mathrm{C}_{2}(\cdot)$ and $\mathrm{C}_{3}(\cdot)$ represent the corresponding cost functions.

Instantaneous net social benefits may be defined as the difference between social benefits and costs:

$$
N B(t)=B(t)-C(t)
$$

The problem for the country or region is to select the optimal combination of these methods so as to maximize the present value of net social benefits. This problem is equivalent to choosing time paths of $\mathrm{y}_{\mathrm{G}}, \mathrm{y}_{\mathrm{H}}$, and $\mathrm{y}_{\mathrm{F}}$ to maximize the objective function:

$$
V=\int_{0}^{\infty} N B(t) \cdot \exp (-r t) d t
$$

where $r$ represents the social rate of discount, subject to the constraint that demand is satisfied, i.e.

$\mathrm{y}=\mathrm{y}_{\mathrm{G}}+\mathrm{y}_{\mathrm{H}}+\mathrm{y}_{\mathrm{F}}$ and other constraints. Economic optimality requires that demand be satisfied at each point in time, for otherwise prices would convey incorrect signals and could induce suboptimal behavior.

The maximization of net social benefits from energy generation subject to satisfying demand is clearly equivalent to minimizing the cost of meeting that demand. This cost minimization approach gives rise to the concept of the marginal social cost of energy supply which is often referred to as the supply price of energy. Thus, a particularly transparent way to approach the problem of the optimal energy generation mix, is to proceed in terms of the social supply price of energy from the different energy sources. The following sections will develop a supply price for each power source.

\section{HYDROELECTRIC SUPPLY PRICE}

Let the cost of electric power generation in the hydroelectric grid system be defined by the cost function:

$$
\mathrm{C}(\mathrm{y}), \mathrm{C}_{\mathrm{y}}>0
$$

This cost function reflects the total costs of operating the existing hydroelectric system (i.e. both fixed and variable costs) at a point of time. $C(\cdot)$, however, does not include investment costs (i.e. sunk costs) or costs associated with future capacity changes. For reasons of mathematical convenience we assume that this cost function is convex and twice continuously differentiable.

Production of electricity is constrained by two factors, the installed generating capacity, denoted as Q, and the availability of water. Thus,

$$
\mathrm{Q} \geq \mathrm{y} \geq 0
$$

In a typical hydroelectric power system, capacity can only be adjusted in relatively large discrete blocks. Generating capacity is, in other words, highly indivisible. This significantly complicates the analysis and resulting optimal management of the system. We will therefore consider $Q$ fixed for this analysis. 
The availability of water depends on the flow rate of the river, which may be taken to be exogenous, and the accumulation of water resources in reservoirs. Referring to the stored water in the reservoirs at time $t$ by $x(t)$ we have:

$$
x^{\prime}(t)=\partial x / \partial t=a(t)-y(t)
$$

where $a(t)$ represents the exogenous inflow of water and $y(t)$ the extraction of water for energy generation.

The simplifying assumption is used that maximization of social benefits from electricity generation is equivalent to maximizing the present value of future consumer and producer surplus. Thus, assuming for the present that capital is fixed, the problem facing the hydroelectric power authorities is:

$$
\operatorname{Max} V=\int_{0}^{\infty}\left[\int_{0}^{q} D(y, t) d y-C(y)\right] \cdot \exp (-r t) d t
$$

subject to:

$$
\begin{aligned}
& Q \geq y \geq 0 \\
& x^{\prime}=a-y \\
& y, x \geq 0
\end{aligned}
$$

where $\mathrm{r}>0$ denotes the social rate of discount and the term $\left[\int_{0}^{q} D(y, t) d y-C(y)\right]$ represents the sum of consumer and producer surpluses at time t.

Equation (9) is only dynamic in a limited sense as the stock variable $\mathrm{x}$ does not appear explicitly in the objective function. This means that the energy generation remains at all times at the optimal equilibrium level given the exogenous variables. If the stock constraint, $x \geq 0$, does not become binding at some point of time, the problem is entirely static.

A Hamiltonian function corresponding to equation (9) may be written as:

$$
H=\int_{0}^{q} D(y, t) d y-C(y)+\sigma(a-y)+\mu_{1} \cdot(Q-y)+\mu_{2} \cdot x
$$

where $\sigma$ and $\mu_{1}$ and $\mu_{2}$ are the Lagrange multipliers for this problem. Along the optimal solution to equation (9), these variables measure the shadow or, in this case, social values of the respective stock variables. More precisely, $\sigma(\mathrm{t})$ measures the increase in the present value of net social benefits, from time $t$ onwards, due to a marginal increase in water reservoir levels. The variable $\mu_{1}$ measures the instantaneous change in social benefits due to a marginal increase in electricity generating capacity at time $t$, and the variable $\mu_{2}(t)$ measures the instantaneous increase in social benefits due to an increase in water levels at time t.

The necessary conditions for solving equation (9) are:

$$
\begin{aligned}
& H_{y}=D(y, t)-C_{y}(y) \leq \sigma+\mu_{1}, y \geq 0, H_{y} \cdot q=0 \\
& \sigma_{1}-r \cdot \sigma=-\mu_{2} \\
& \mathrm{Q} \geq \mathrm{y}, \mu_{1} \geq 0,(\mathrm{Q}-\mathrm{y}) \cdot \mu_{1}=0
\end{aligned}
$$




$$
\begin{aligned}
& x^{\prime}=a-y \\
& x \geq 0, \mu_{2} \geq 0, x \cdot \mu_{2}=0
\end{aligned}
$$

These necessary conditions reveal a set of socially optimal rules for electricity pricing. Provided there is some production of electricity, according to equation (14), the optimal supply price of hydropower, $\mathrm{p}_{\mathrm{H}}$, is given by:

$$
P_{H}=D(y, t)=C_{y}(y)+\sigma+\mu_{1}
$$

The first term in the supply price is the marginal instantaneous cost of generating electricity. The second, $\sigma$, reflects the social cost of using water for electricity generation. It can be shown that if the water supply is adequate for all future periods, then $\sigma=0$ at all $\mathrm{t}$. The third term, $\mu_{1}$, measures the social value of a marginal increase in generating capacity. If there is excess capacity at time, $\mu_{1}=0$, otherwise $\mu_{1} \geq 0$. For investment to be optimal, $\mu_{1}$ must at least equal the marginal cost of investment.

The variables $\sigma$ and $\mu_{1}$ in equation (19) reflect the importance of water availability and investment costs for the optimal supply price of hydropower. The movement of $\sigma$ and $\mu_{1}$ over time is given by conditions (14) through (18). Two important special cases may be discerned from this analysis.

\section{CASE 1: WATER SUPPLY NOT BINDING}

If the water supply is abundant in the sense that the $x \geq 0$ constraint will never become binding, the electricity pricing rules are relatively simple. In that case they are:

$$
\begin{aligned}
& p_{H}=D(y, t)=C_{y}(y), \text { if } \mathrm{Q}>\mathrm{y}, \text { i.e., excess capacity } \\
& p_{H}=D(Q, t), \text { if } \mathrm{Q}=\mathrm{y}, \text { i.e., full utilization of capacity }
\end{aligned}
$$

It is important to realize that to follow these rules just requires knowledge of the current situation facing the hydroelectric authority. Assuming for the moment that demand increases at a constant exponential rate (i.e., the inverse demand function can be written as $D(y, t)=D(y) \cdot \exp (\alpha \cdot t), \alpha>0)$, the optimal time path of supply price will be similar to Figure 1.

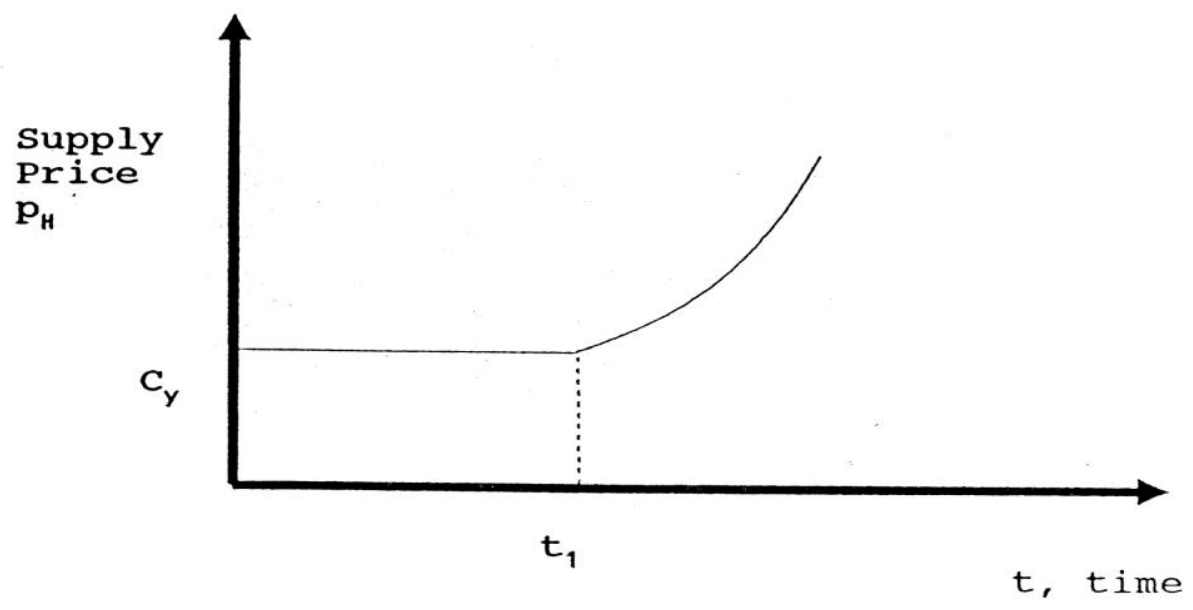

Figure 1

Hydroelectric Supply Price: Abundant Water with No Investment 
Figure 1 illustrates two possible phases. In the first phase, from $t=0$ to $t=t_{1}$, there is excess capacity and equation (20) applies. In the second phase, from $t=t_{1}$ onwards, there is full utilization of capacity. Therefore, the supply price must adjust so as to satisfy the demand and equation (21) applies. is given by:

At some point during phase 2 it will become optimal to invest in additional capacity. The condition for that

$$
V\left(Q_{1}\right)-V\left(Q_{0}\right) \geq I
$$

where $V\left(Q_{1}\right)$ represents the value of the optimal program under some new capacity, $\mathrm{Q}_{1}$, and $V\left(Q_{0}\right)$ the value of the optimal program under the old capacity, $\mathrm{Q}_{0}$. (I) represents the cost of investing in additional capacity.

As suggested by equation (22), investment decisions require knowledge about future conditions since $V\left(Q_{1}\right)$ and $V\left(Q_{0}\right)$ involve the entire future path of electricity generation. More precisely:

$$
V\left(Q_{1}\right)=\int_{0}^{\infty}\left[\int_{0}^{q} D\left(y^{*}, t\right) d y-C\left(y^{*}\right)\right] \cdot \exp (-r t) d t
$$

Where $y^{*}$ represents the optimal path of electricity production and bounded by the constraint $Q_{1} \geq y^{*}$. A similar expression holds for $V\left(Q_{0}\right)$. Thus, the optimal investment decisions require perfect foresight for the remainder of the program horizon. Only in certain rare circumstances is it possible to base the optimal investment decisions on current data. One such case is when future electricity demand is guaranteed not to fall below the demand at the time of the investment.

Once a discrete addition to electricity generation capacity has taken place, the situation reverts to one described by equations (20) and (21). Thus, allowing discrete investments, the time path of the electricity supply price is described in Figure 2.

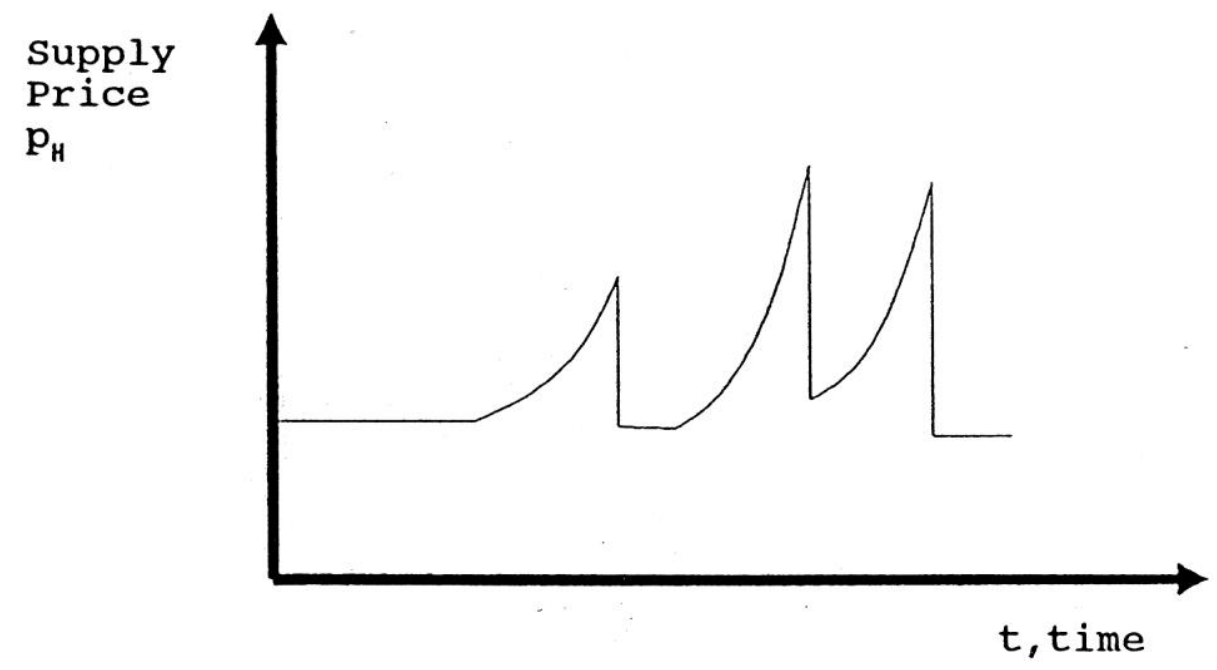

Figure 2.

Hydroelectric Supply Price: Abundant Water 


\section{CASE 2: WATER SUPPLY BINDING}

If it is expected that at some point in the future water will become scarce in the sense that the $\mathrm{x} \geq 0$ becomes binding, this will be reflected in the current shadow value of water, $\sigma$. Therefore, as suggested by equation (19), the social supply price of water will have to be adjusted upwards. The more imminent the water shortage the higher is $\sigma$ and the higher the supply price of electricity. This is illustrated in Figure 3.

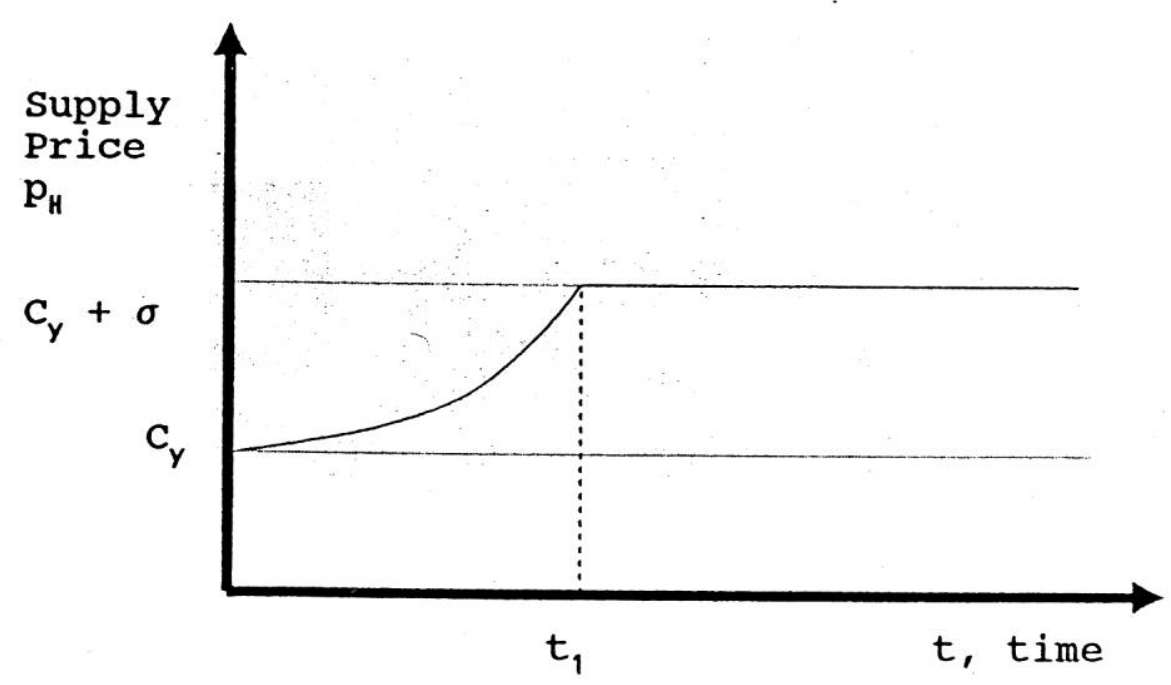

Figure 3.

Hydroelectric Supply Price: Water Shortage

Figure 3 illustrates the case where demand is time invariant, i.e. $D(y, t)=D(y)$, but water reservoirs are declining and running dry at time $t_{1}$. Therefore, prior to $t_{1}$, the supply price rises to encourage conservation and to postpone the time of water shortage. From $t_{1}$ onwards, electricity supply relies on the instantaneous water flow, $a(t)$, and if this is constant so will the supply price be.

The economic rationale for increasing the supply price of electricity when water shortage is expected is to encourage conservation. When reservoirs run dry, power authorities are faced with a block interval in the sense that they would like to make $\mathrm{x}$ negative but are unable to do so. This situation suggests prior adjustments in the optimal paths.

Clearly, potential water shortage greatly complicates the determination of optimal price. First, since running out of stored water at some point in the future is a distinct possibility in most hydroelectric systems, the pricing of energy can no longer rely on current data. Foresight and prediction become crucial for identifying the optimal pricing path. Second, due to this constraint, the calculation of optimal prices becomes more complex, even when good predictions are available. Third, actual price profiles become more uneven and jagged than before.

\section{GEOTHERMAL ENERGY SUPPLY PRICE}

In order to analyze the supply price, we need to first consider a geothermal field consisting of a number of well. Hot water continuously flows into these wells. Let $x(t)$ represent the level of water of a given temperature in the wells at time t. It stands to reason that the rate of change of $\mathrm{x}$ depends on the level of $\mathrm{x}$ itself. Let this natural rate of change be given by the function $\mathrm{G}(\mathrm{x}(\mathrm{t}))$. We assume that $\mathrm{G}(0)>0$ and there exists a natural positive equilibrium water level, $x^{*}$, say, such that $G\left(x^{*}\right)=0$ and that $G(X)>0$ for all $x$ in the interval $\left(0, X^{*}\right)$. For reasons of mathematical convenience we further assume that $\mathrm{G}(\mathrm{x})$ is twice continuously differentiable and concave. The shape of $\mathrm{G}(\mathrm{x})$ is illustrated in Figure 4. 


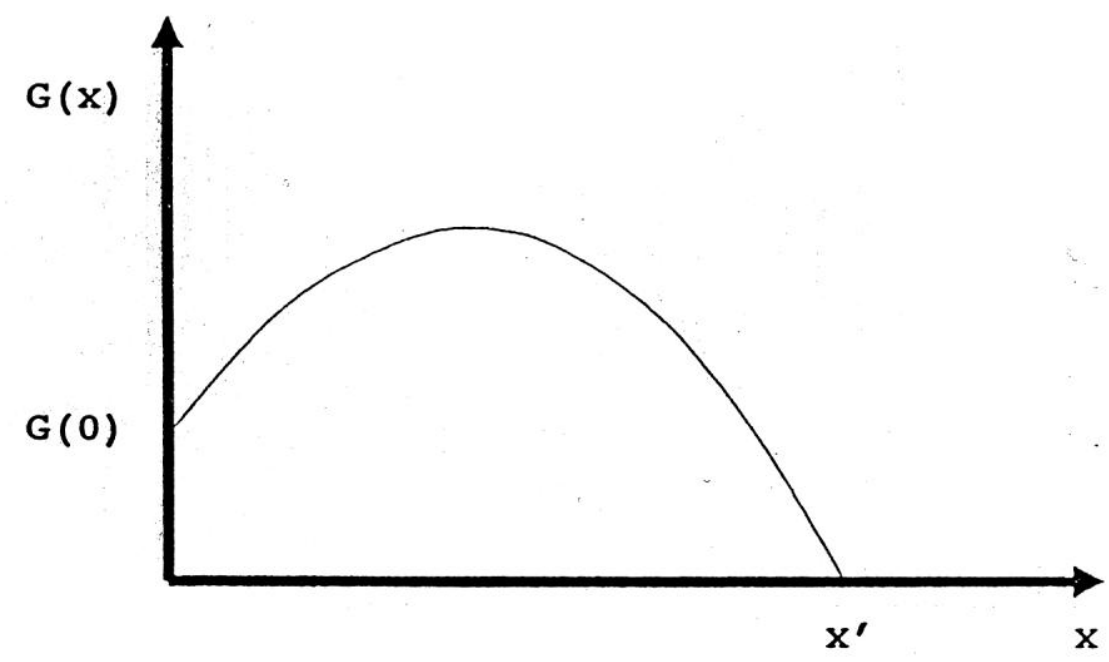

Figure 4

Natural Water Inflow Function, G(x)

Hot water is being extracted from the wells and supplied to consumers at the rate of $y(t)$. Thus, the water level in the wells changes according to:

$$
x^{\prime}(t)=\partial x \partial t=G(x(t))-y(t)
$$

The instantaneous cost of extracting water from the field is taken to increase with the rate of extraction, $y$, and decrease with the available level of water, $x$, such that:

$$
C(t)=C(y, x), C y>0, C x<0
$$

This function is assumed to be twice continuously differentiable and convex in both of its arguments.

As in the case of the hydroelectric power generation example discussed above, the production of geothermal energy is constrained in two ways. One is the capacity of the system to pump and pipe hot water to consumers. Referring to this constraint by the symbol Q, we have:

$$
Q \geq y
$$

The other constraint is the availability of hot water in the wells, $\mathrm{x}$. Therefore, $\mathrm{x}$ cannot be made negative.

$$
x \geq 0
$$

In countries like Iceland, the second constraint is much more important than the first one. One reason is that the delivering capacity can normally be adjusted in relatively small steps to accommodate demand. On this basis and to avoid unnecessary complications let us assume that investments in capacity are perfectly divisible so that:

$$
Q^{\prime}=i
$$

where, i represents net investment. 
The problem facing power authorities is thus:

$$
\operatorname{Max} V=\int_{0}^{\infty}\left[\int_{0}^{q} D(y, t) d y-C(y, x)-s \cdot i\right] \cdot \exp (-r t) d t
$$

subject to:

$$
\begin{aligned}
& Q \geq y \geq 0 \\
& Q^{\prime}=i \\
& x^{\prime}=G(x)-y \\
& y, x \geq 0
\end{aligned}
$$

where, $r>0$ denotes the social rate of discount, $s$, the unit price of investment, and the term $\left[\int_{0}^{q} D(y, t) d y-C(y, x)-s \cdot i\right]$ represents the sum of consumer and producer surplus at time t.

The solution to the above problem has an explicitly dynamic character, since the stock variable, $\mathrm{x}$, appears in the objective function. The following phase diagram explains this situation.

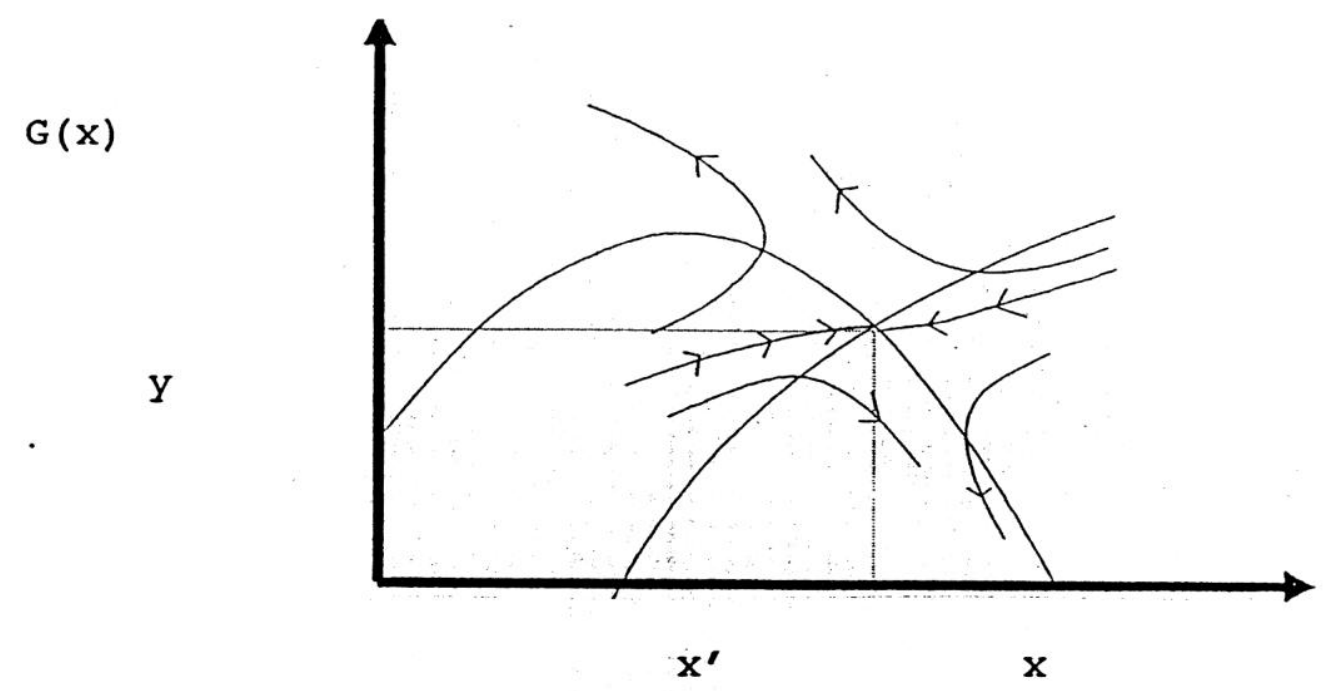

Figure 5

Geothermal Extraction: Phase Diagram

The phase diagram in Figure 5 shows that the optimal interior solution involves a dynamic adjustment to a saddle point equilibrium $\left(\mathrm{y}^{*}, \mathrm{x}^{*}\right)$. Given an infinite horizon, only paths to $\left(\mathrm{y}^{*}, \mathrm{x}^{*}\right)$ can be optimal. Notice, however, that qualitatively different cases are possible. For instance, it may well be the case that the $y^{\prime}=0$ schedule does not intersect the $\mathrm{x}^{\prime}=0$ schedule for any $\mathrm{y}>0$. This would be the case for a very low natural rate of hot water renewal or weak energy demand. In that case zero extraction of hot water would be optimal.

The optimal energy pricing rule is thus: 


$$
P_{G}=C_{y}(y, x)+\sigma+\mu
$$

where $C_{y}(y, x)$ represents the marginal cost of the water supply, $\sigma$ is the social shadow value of water in the wells, and $\mu$ is the shadow value of the supply capacity. Since $\mu=0$ unless the capacity is fully utilized, equation (30) reduces to:

$$
P_{G}=C_{y}(y, x)+\sigma
$$

When delivering capacity is fully utilized, $\mu=r \cdot s$, where $\mu$ equals the marginal capacity costs. In this case, equation becomes:

$$
P_{G}=C_{y}(y, x)+\sigma+(r \cdot s)
$$

Given the assumptions, the shadow value of hot water in the geothermal wells, $\sigma$, is positive provided the field is utilized. In addition, this value increases monotonously as the available water level is drawn down. If it is expected that the optimal utilization path will exhaust the water level at some point in time, $\sigma$ will reflect this and increase faster. Thus, in this case, foresight is needed to calculate the optimal supply prices.

As in the hydroelectric case we can illustrate the time path of the geothermal supply price given constant proportional growth of demand. This is shown in Figure 6.

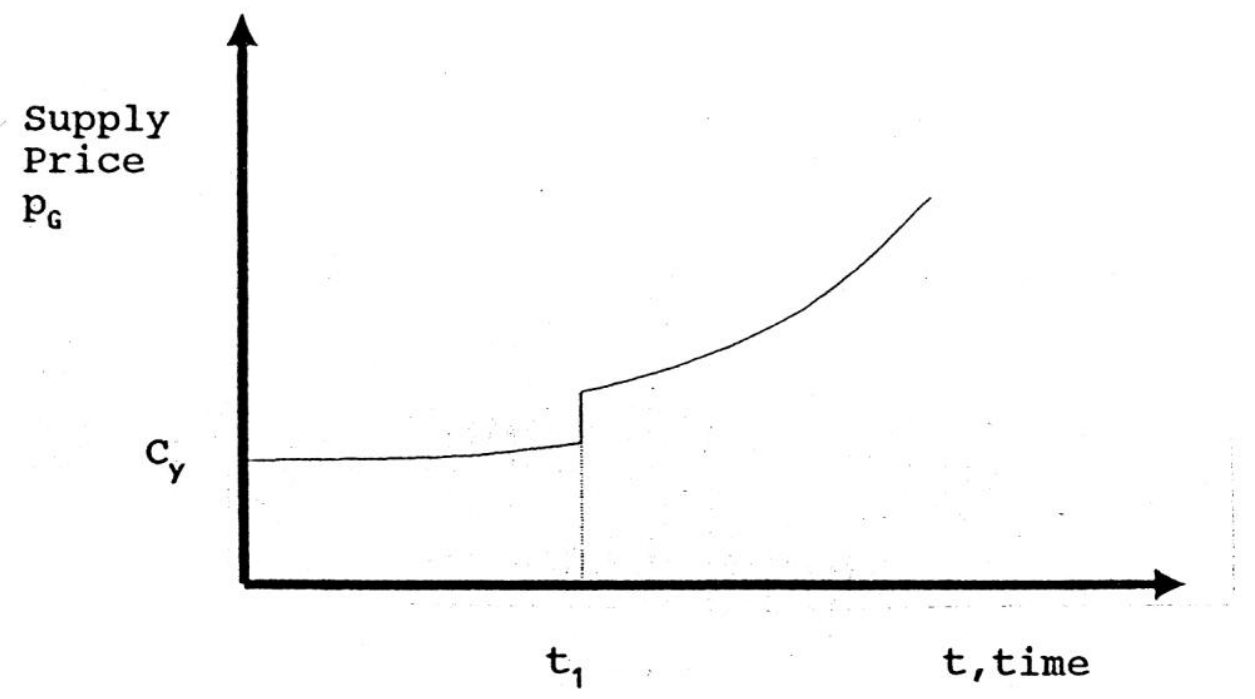

Figure 6

Geothermal Supply Price: No Field Investments

Figure 6 essentially illustrates two phases for the geothermal field. In the first phase, $t=0$ to $t=t_{1}$, there is excess capacity in the delivery system and equation (31) applies. In the second phase, from $t=t_{1}$ onwards, there is full utilization of capacity and equation (32) applies.

At some point during phase 2, it may become optimal to invest in additional field development capacity such as drilling new wells. The optimal condition for discrete investment of this nature is given by equation (23) as before. If such investment is found to be optimal, water shortage will be alleviated and the path of supply price over time may become jagged as illustrated in Figure 7. 


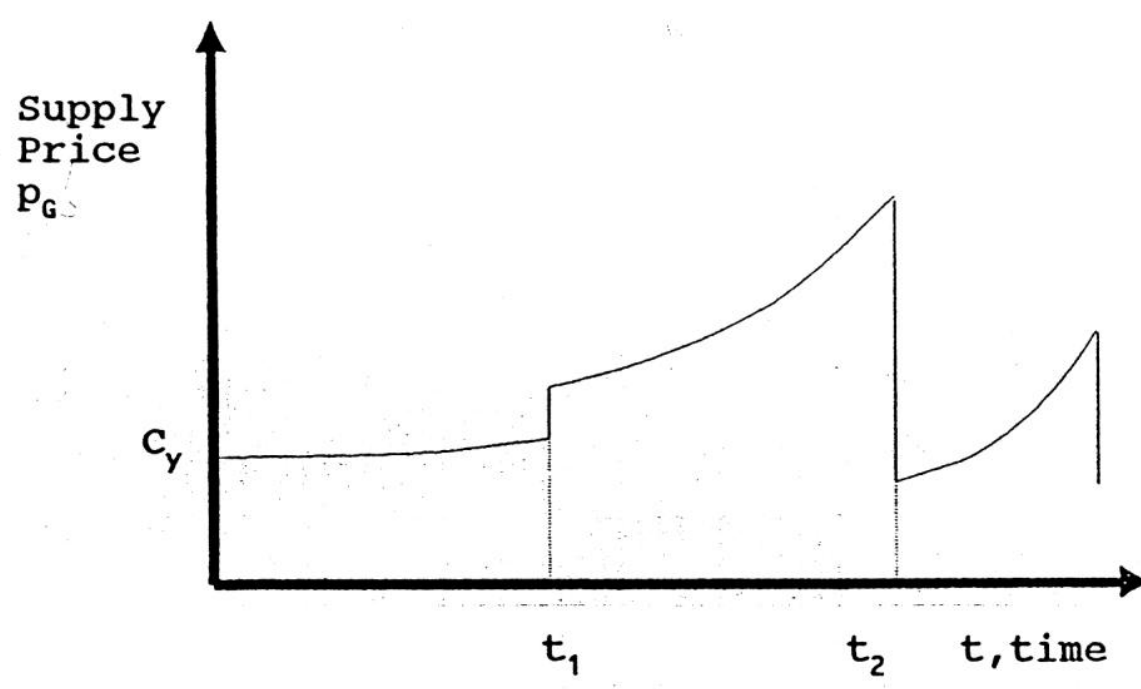

Figure 7

Geothermal Supply Price: Field Investments

It should be noted that under the situation of discrete investments, the optimal pricing rules may not generate income sufficient to pay for investment costs. In that case, alternative funding will have to be found.

\section{FOSSIL FUEL ENERGY SUPPLY PRICE}

Let the cost of energy generation by burning fossil fuel (e.g. coal, oil, natural gas) in existing capacity be represented by the twice continuously differentiable and convex cost function:

$$
C(y), C_{y}>0
$$

Production of fossil fuel energy is constrained by the installed capacity. Thus, referring to the installed capacity by Q:

$$
Q \geq y
$$

Assume in reality that fossil fuel energy generation capacity can be adjusted upwards and downwards approximately on a continuous basis by changes in investment. It should, however, be recognized that this requires that capacity units are small and that there exists a well functioning resale market for fossil fuel capacity. Thus, omitting depreciation, capacity changes according to:

$$
Q^{\prime}(t)=i
$$

where i refers to investment.

Finally, let the investment cost per unit of capacity be represented by $s>0$. Given these specifications, the problem facing fossil-fuel energy utilities is:

$$
\operatorname{Max} V=\int_{0}^{\infty}\left[\int_{0}^{q} D(y, t) d y-C(y)-(s \cdot i)\right] \cdot \exp (-r t) d t
$$


subject to:

$$
Q \geq y \geq 0
$$

$$
Q^{\prime}=i
$$

$$
y \geq 0
$$

where, as before, $r>0$ denotes the social rate of discount and the term [ $\left.\int_{0}^{q} D(y, t) d y-C(y)-(s \cdot i)\right]$ represents the sum of consumer and producer surpluses at time $t$.

It is worth noting that the only stock variable in this problem is the capacity level, Q. However, given the malleability of the fossil fuel capacity, Q will be adjusted to output, y, at each point in time. Given this, the supply price of fossil fuel is given by the following single equation

$$
P_{f}=C_{y}(y)+r \cdot s
$$

The assumption of perfect malleability of fossil fuel capacity is an approximation. Any changes to this assumption would require some modification of equation (40), but these changes would probably be minor.

\section{JOINT UTILIZATION OF DIFFERENT ENERGY SOURCES}

The social supply price schedules of hydroelectric, geothermal, and fossil fuel were derived in the previous sections. These schedules, defined in equations (19), (31), and (40) give the respective supply prices as functions of the amount of energy generated as well as other variables. From this, we can examine the conditions for joint utilization of these energy sources..

For purposes of this analysis it is assumed that any energy demand would be met at the lowest available supply price at each point of time. If that were not the case, the present value of social benefits would not be maximized. This condition of lowest available supply price can be formally stated as:

$$
\mathrm{D}\left(\mathrm{y}_{\mathrm{H}}, \mathrm{y}_{\mathrm{G}}, \mathrm{y}_{\mathrm{F}}, \mathrm{t}\right)=\operatorname{Min}\left[\mathrm{p}_{\mathrm{H}}\left(\mathrm{y}_{\mathrm{H}}\right), \mathrm{p}_{\mathrm{G}}\left(\mathrm{y}_{\mathrm{G}}\right), \mathrm{p}_{\mathrm{F}}\left(\mathrm{y}_{\mathrm{F}}\right)\right] \text {, all } \mathrm{t},
$$

where $\mathrm{p}_{\mathrm{H}}\left(\mathrm{y}_{\mathrm{H}}\right), \mathrm{p}_{\mathrm{G}}\left(\mathrm{y}_{\mathrm{G}}\right)$, and $\mathrm{p}_{\mathrm{F}}\left(\mathrm{y}_{\mathrm{F}}\right)$ represent the social supply prices of hydroelectric, geothermal, and fossil fuel respectively.

Thus, the condition for joint utilization of any two energy sources at a point in time is:

$$
p_{i}\left(y_{i}\right)=p_{j}\left(y_{j}\right) \text {, for } y_{i} \text { and } y_{i} \geq 0
$$

Given the exogenous demand, $\mathrm{D}(\mathrm{y}, \mathrm{t})$ and the respective supply price functions, it is clear that equations (41) and (42) fully specify the optimal joint utilization of the three energy sources at a given point in time. The conditions are:

$$
\begin{aligned}
& D(y, t)=p_{H}\left(y_{H}\right), \text { or } y_{H}=0 \\
& D(y, t)=p_{G}\left(y_{G}\right), \text { or } y_{G}=0 \\
& D(y, t)=p_{F}\left(y_{F}\right), \text { or } y_{F}=0
\end{aligned}
$$




$$
y=y_{H}+y_{G}+y_{F}
$$

This is illustrated in Figure 8. This illustrates short run supply price schedules for the three energy sources. In the figure geothermal energy has the lowest supply price, hydroelectric a slightly higher supply price, and fossil fuel the highest supply price at low output levels.

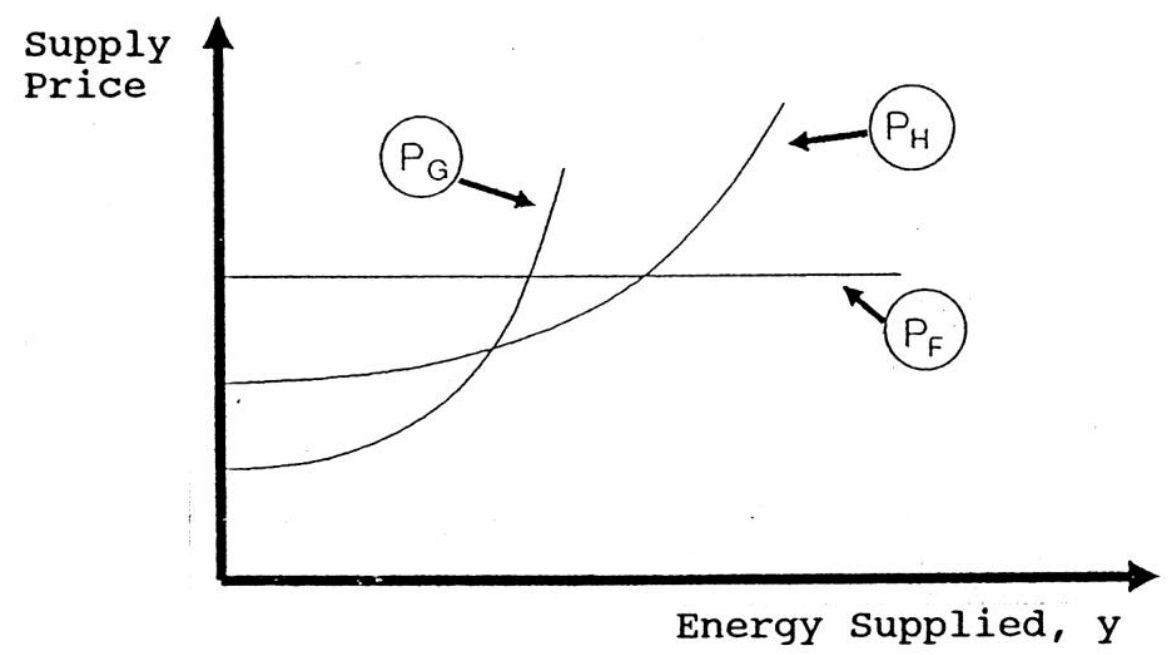

Figure 8

Short Run Supply Prices: Examples

The aggregate inverse supply schedule, obtained as a horizontal sum, (for given supply prices) of the three individual supply prices, is shown in Figure 9.

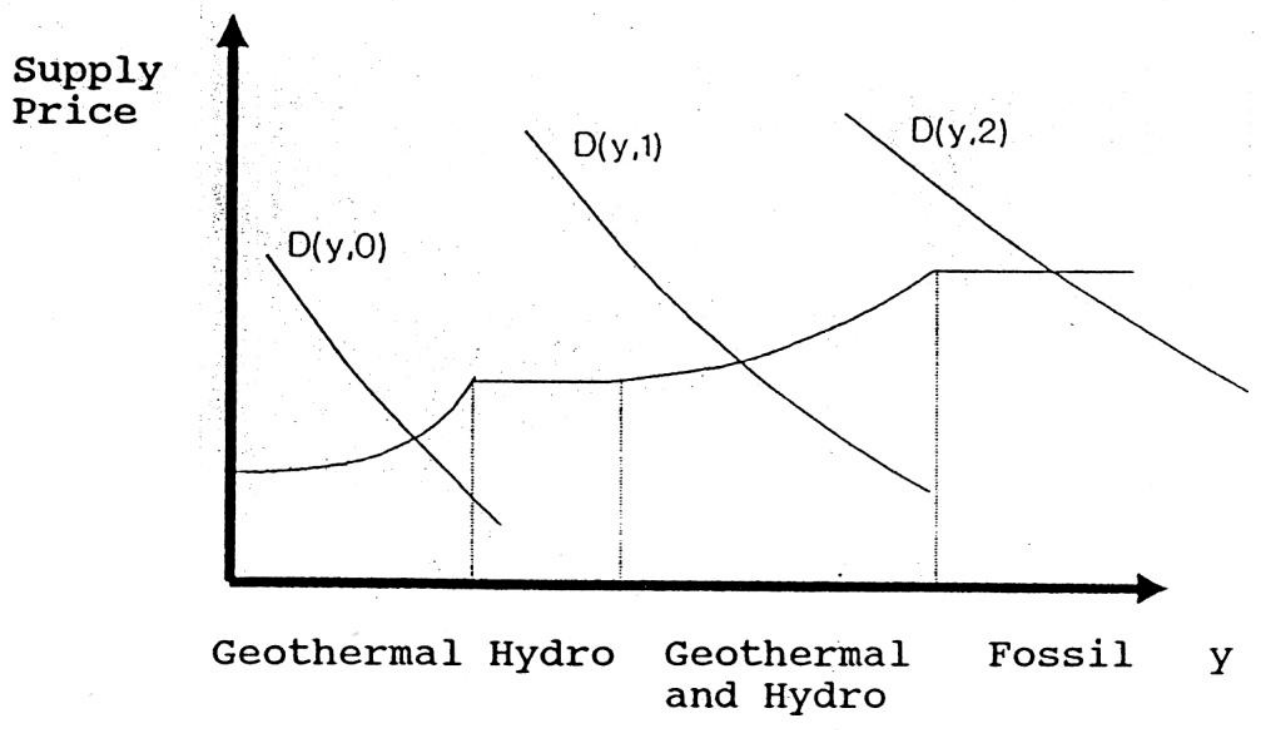

Figure 9.

Aggregate Supply Price: An Example 
This also shows the energy demand curves for the three different times, namely $t=0, t=1$, and $t=2$. Assuming that demand increases with time, the demand curves move to the right with time.

Figure 9 shows that in this example only geothermal energy should be used when aggregate demand is low. For higher demand, the supply price of geothermal energy increases and hydroelectric energy becomes economical. Only hydroelectric energy will be used to meet the growing demand while it can be supplied at a fixed supply price. When the supply price of hydroelectric energy starts to rise, growing demand will be met with a combination of hydroelectric and geothermal power sources. In Figure 9, marginal hydroelectric and geothermal supply prices eventually reach the fossil fuel supply price. At this point fossil fuel energy demand will meet the additional demand.

This example demonstrates that joint utilization of different energy sources may very well be optimal in the short run. But does this also apply in the long run? The main reason for the joint utilization effect described above is the capacity constraints on low cost energy sources in the short run. Presumably, in the long run, the least cost alternative will be expanded by investment and the associated capacity constraints correspondingly relaxed.

While this is certainly true to some extent, there are at least two reasons why joint utilization of energy sources may also be optimal in the long run. The first has to do with the limitations of nature. It may well be the case that least cost energy alternatives simply cannot be expanded by investment because of shortage of the appropriate natural resources. This clearly holds for all three of the sources of energy considered in this paper, hydroelectric, geothermal, and fossil fuel. The long run, therefore, might actually not be too dissimilar to the one depicted in Figure 9.

The other reason for joint utilization of different energy sources in the long run has to do with the cyclical nature of energy generation and demand. As indicated in Figure 9, it may be optimal to meet daily and seasonal energy demand peaks and production lows by utilizing more than one energy source with different economic and technical characteristics. This may hold even in the long run. The question is whether investment in little used capacity of the low variable cost alternative is optimal or not. The relevant condition to investigate is given in equation (1.24).

In conclusion, countries like Iceland face significant decisions regarding future develop of their available energy sources. Given the recent financial and governmental collapse of Iceland, it is important that they promote these valuable energy sources in order to help insure a sound economic future. The model presented in this paper demonstrates the feasibility of co-utilization of different energy sources.

\section{AUTHOR INFORMATION}

Dr. Duane J. Rosa is Professor Economics and Regional Division Director of the Texas Transportation Institute at West Texas A\&M University. He has been with the university since 1984. Dr. Rosa holds a Ph.D. in economics from Texas Tech University and Master's degrees in engineering and economics from the University of Oklahoma and the University of Nevada Las Vegas. He teaches courses in environmental economics, managerial economics, and microeconomic theory. Dr. Rosa was a Fulbright Professor at the University of Iceland in 1992 and 1994. His research and professional publications are in the areas of energy, water resources and transportation.

\section{REFERENCES}

1. Arrow, K.J. (1968), “Optimal Capital Policy with Irreversible Investment,” In J.N. Wolve (ed.), Value, Capital and Growth, Edinburgh University Press.

2. Hilmarsson, T. (2003), "Energy and Aluminum in Iceland," Platts Aluminum Symposium, Phoenix, AZ.

3. Landsvirkjun - National Power Company of Iceland (2007), Electricity Production.

4. Landsvirkjun - National Power Company of Iceland (2007), Karahnjukar Hydropower Project.

5. Landsvirkjun - National Power Company of Iceland (1992), Feasibility Study for Laying of Submarine Cable.

6. Orkustofnun - Iceland Energy Authority, (2007), Energy Statistics in Iceland. 
7. Orkustofnun - Iceland Energy Authority, (2007), Energy in Iceland, Historical Perspective, Present Status, Future Outlook.

8. Pontryagin, L., Boltyanski, V., Gamkrelidze, R., Mishchenko, E. (1962), The Mathematical Theory of Optimal Processes, John Wiley Publisher.

9. Valfells, A., Fridleifsson, I., Helgason, T., Ingimarsson, J., Thoroddsson, G., Sophusson, F. (2004), Sustainable Generation and Utilization of Energy The Case of Iceland, $19^{\text {th }}$ World Energy Congress, Sydney, Australia.

10. World Energy Council (2007), Survey of Energy Resources 2007 - Hydropower.

\section{$\underline{\text { NOTES }}$}

